\title{
Bowel obstruction due to the tightening of a loose bowel adhesion with uterus enlargement during pregnancy
}

\author{
Ghazi Laamiri ${ }^{1,2}$, Montassar Ghalleb ${ }^{1,2}$, Nouha Ben Ammar ${ }^{1,2}$, Slim Zribi ${ }^{1,2}$, \\ Mongi Mighri ${ }^{1,2}$, Mahdi Bouassida ${ }^{1,2}$, Hassen Touinsi ${ }^{1,2}$ \\ ${ }^{1}$ DEPARTMENT OF GENERAL SURGERY, HOSPITAL MOHAMED TAHER EL MAAMOURI NABEUL, TUNISIA \\ ${ }^{2}$ FACULTY OF MEDICINE TUNIS EL MANAR, TUNISIA
}

\begin{abstract}
Introduction. Acute intestinal obstruction during pregnancy is a rare digestive surgical emergency. Generally, it is associated with significant maternal and fetal mortality. The diagnosis is difficult, often delaying the therapeutic management. It is reported an exceptional association of acute intestinal obstruction due to a band adhesion that is put into tension as the uterus enlarges. Case Report. A 35 years old Caucasian pregnant woman with a past medical history of appendectomy was examined and found with abdominal pain, severe vomiting, and bowel obstruction. The patient underwent surgery. Per operatively, the obstruction was caused by an adhesion put into tension by the enlargement of the uterus. The postoperative course was uneventful and the patient was discharged on day 2. Conclusions. The etiological diagnosis of acute intestinal obstruction during pregnancy is difficult. Surgery is the cornerstone of the treatment and the management varies depending on the intraoperative findings and the condition of the patient.
\end{abstract}

Category: Case Presentation

Received: July 12, 2020

Accepted: September 19, 2020

Keywords:

small bowel obstruction, pregnancy, acute abdomen, abdominal adhesions, uterine fibroid

*Corresponding author:

Montassar Ghalleb,

Department of Surgical Oncology, Salah Azaiez Institute, Boulevard 9 Aavril 1006, Tunis, Tunisia

E-mail: montaghalleb@gmail.com

\section{Introduction}

Bowel obstruction in pregnancy is a high-risk situation for both mother and baby, with a maternal mortality ranging from 2 to $4 \%$ [1]. Fetal loss is estimated from 13 to $17 \%$. Preterm delivery occurs in about $45 \%$ of the cases [2,3].

Adhesions were the most common pathology encountered in 30-50\% of cases, followed by internal hernias and volvulus [3]. The most common presenting symptoms were abdominal pain $(88 \%)$, vomiting $(67 \%)$, examination findings of tenderness $(49 \%)$, and abdominal distension (28\%) [4].

The purpose of this report is to present a rare case of bowel obstruction due to a band adhesion that is put into tension as the uterus enlarges. From the documentation performed, this is among the few cases reported in the literature.

\section{Case Presentation}

We report the case of a 35 years old Caucasian woman, G2P1. She was 28 weeks pregnant, without being known with chronic diseases. Her first pregnancy, two years before this case, was complicated with acute appendicitis. She had no other surgical interventions in his medical history. She consulted the emergency of our institution and was admitted to surgery department for bowel occlusive syndrome, which had been evolving for 3 days. At the presentation, she had abdominal pain associated with severe vomiting and bowel occlusion.

Her blood pressure was $12 / 7 \mathrm{~mm} / \mathrm{Hg}$ and she had a normal heart rate. The body temperature was $37,1^{0}$ Celsius.

The abdominal examination was remarkable for a gravid uterus and moderate tenderness to palpation of the right iliac fossa. A rectal examination found an empty rectum. Fetal heart rate fell within normal range and uterine contractions were absent. Routine blood tests were without significant changes.

The diagnosis of acute adhesive obstruction was made and a laparotomy was performed. Intraoperatively, we found that the intestinal occlusion was due to a single band adhesion originating from the site of previous appendectomy connecting with a subserosa uterine myoma of $4 / 3 \mathrm{~cm}$, which adhered and tensed a segment of the small intestine (Figure 1). 
This adhesion was put into tension with the enlargement of the uterus, which intensified as the pregnancy progressed. The section of the band resolved the obstruction and no signs of bowel compromise were noted thereafter (Figure 2). The surgery was uneventful, lasted about 100 min with minimal blood loss.

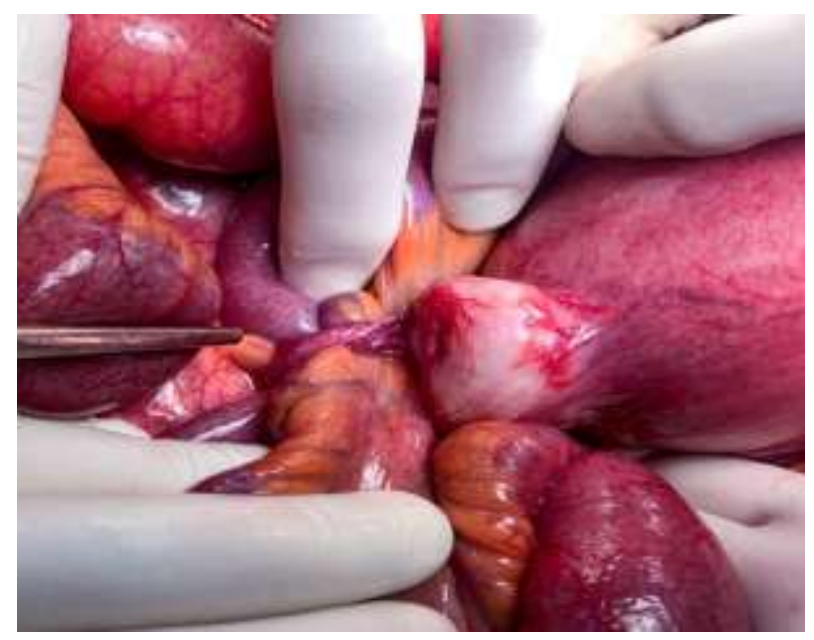

Figure 1. Detection and aspect of intraoperative adhesion.

\section{Discussions}

Abdominal pain during pregnancy can provide a wide range of differential diagnoses, due to the increased abdomen volume [5]. The causes of abdominal pain can be divided into three different groups: pregnancy-related causes, causes exacerbated by pregnancy, and nonpregnancy-related causes. The latter can be further divided into abdominal and extra abdominal causes [1,3]. Conditions unique to gynecologic pathologies include
The postoperative course was without complications. After the first postoperative day, the patient was mobilized and received a clear liquid diet. The next day, the patient returned to normal bowel function, so he benefited from a regular diet. She was finally discharged home after two days.

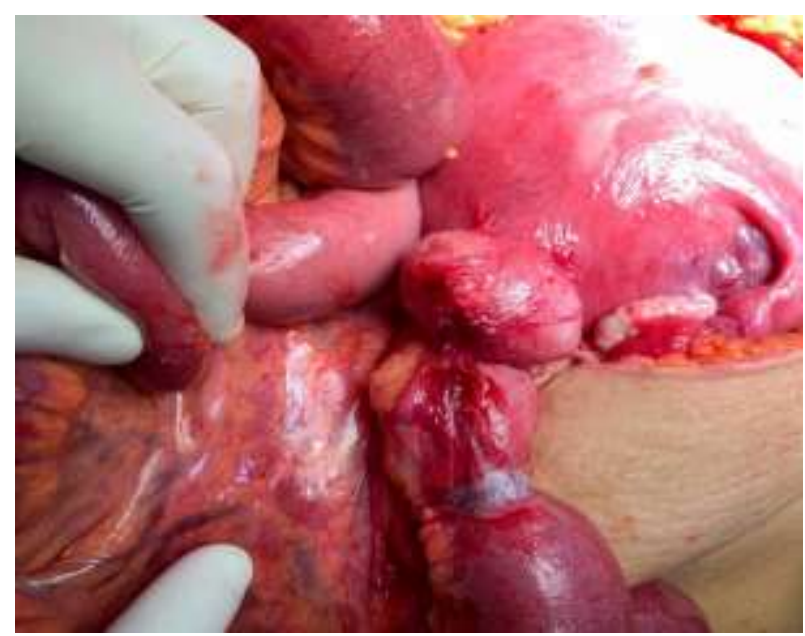

Figure 2. Intraoperative appearance after adhesion section.

placental abruption, uterine rupture, preeclamptic toxemia, and the HELLP syndrome.

The non-pregnancy-related causes of abdominal pain are the same as those found in the general setting of the acute abdomen, such as acute appendicitis that remains the most common non-obstetric surgical emergency during pregnancy. This condition is followed by cholecystitis, pancreatitis, and bowel obstruction. The main etiologies have been summarized in table one (Table 1) [2].

Table1. Most frequent causes of abdominal pain during pregnancy.

\begin{tabular}{|c|c|c|c|}
\hline Pregnancy-related causes & Non-pregnancy-related causes & Extra-abdominal causes & $\begin{array}{l}\text { Causes exacerbated by } \\
\text { pregnancy }\end{array}$ \\
\hline $\begin{array}{l}\text { Miscarriage } \\
\text { Ectopic pregnancy } \\
\text { Molar pregnancy } \\
\text { Ovarian cyst (torsion, } \\
\text { hemorrhage, rupture) } \\
\text { Degeneration of uterine fibroids } \\
\text { Round ligament pain } \\
\text { Placental abruption } \\
\text { Acute fatty liver } \\
\text { Abdominal pregnancy } \\
\text { HELLP syndrome } \\
\text { Uterine Rupture } \\
\text { Fibroid degeneration } \\
\text { Fallopian tube torsion } \\
\text { Uterine torsion } \\
\text { Rupture rectus muscle } \\
\text { Polyhydramnios } \\
\text { Symphysis diastasis } \\
\text { Intraperitoneal bleed }\end{array}$ & $\begin{array}{l}\text { Appendicitis } \\
\text { Cholecystitis } \\
\text { Biliary colic } \\
\text { Acute pancreatitis } \\
\text { Peptic ulcer } \\
\text { Urolithiasis } \\
\text { Intestinal obstruction } \\
\text { Inflammatory bowel disease } \\
\text { Rupture aneurysm trauma } \\
\text { Gastroenteritis } \\
\text { Porphyria Sickle cell crisis } \\
\text { Deep vein thrombosis } \\
\text { Somatic Symptom Disease }\end{array}$ & $\begin{array}{l}\text { Cardiac pain } \\
\text { Herpes zoster infection } \\
\text { Non-specific abdominal } \\
\text { pain }\end{array}$ & $\begin{array}{l}\text { Endometriosis } \\
\text { Gallbladder disease } \\
\text { Acute cystitis } \\
\text { Acute pyelonephritis } \\
\text { Musculoskeletal pain } \\
\text { Gastroesophageal reflux } \\
\text { disease }\end{array}$ \\
\hline
\end{tabular}


Small bowel obstruction is an unusual cause of abdominal pain during pregnancy.

Usually, there are three time periods associated with the increased frequency of developing an intestinal obstruction in pregnancy, that is, 16th-20th week, the 36th week, and immediate post-partum [2].

Symptoms of intestinal obstruction in pregnancy include abdominal pain (98\%), nausea and vomiting (82\%), and constipation (30\%) [1].

The physical examination can vary, but the most reliable findings include abdominal tenderness and abdominal peristalsis in $71 \%$ and $55 \%$ of the patients, respectively [6].

The clinical diagnosis of bowel obstruction presents a challenge because of non-specific symptoms and a graviduterus limiting the effectiveness of physical-examination and imaging.

The commonest etiologies are adhesions (30\%), hernias $(25 \%)$, and volvulus $(24 \%)$. The commonest site was the ileum (37\%) [7].

Bowel obstruction can induce Maternal complications such as death (4\%), bowel perforation (14\%), hypovolemic shock (12\%), and sepsis (8\%). It can also be responsible for perinatal complications including prematurity $(45 \%)$, low birth weight (11), stillbirths $(9 \%)$, and neonatal death $(4 \%)$ [8].

In our case, as the uterine fundus rose out of the pelvis, the band of dense adhesion created in her previous appendectomy, and connected with the uterine fibroid caused complete obstruction by trapping a segment of the small bowl underneath.

Diagnosis typically requires imaging. Plain radiographs are often ordered, they cannot exclude the diagnosis. An ultrasound scan may demonstrate fluid-filled bowel loops. Abdominal CT is highly sensitive and specific in detecting small bowel obstruction that is the diagnostic technique of choice in non-pregnant patients. However, in pregnant patients, CT exposes the fetus to ionizing radiation. MRI is capable of providing large field-of-view images of maternal abnormalities. Furthermore, images obtained with MRI do not expose the fetus to ionizing radiation [9].

Concerning the treatment, non-operative management may be achieved with fluid replacement and decompression via a nasogastric tube and intravenous supplementation with fluids and electrolytes. Surgical management will depend on the severity of condition and gestation $[1,3,10]$.

This can be achieved with or without concurrent delivery although delivery may be required to gain access or where there are concerns over fetal wellbeing.

\section{Conclusions}

The diagnosis of intestinal obstruction in pregnancy may be difficult. Symptoms associated with pregnancy (pain, distension, vomiting, and constipation) themselves may be a source of confusion in making a diagnosis. Gestational intestinal obstruction is associated with significant maternal and fetal mortality. Clinical suspicion of the presence of obstruction and aggressive intervention is required to decrease the morbidity and mortality of this rare complication of pregnancy.

\section{Conflict of interest disclosure}

There are no known conflicts of interest in the publication of this article. The manuscript was read and approved by all authors.

\section{Compliance with ethical standards}

Any aspect of the work covered in this manuscript has been conducted with the ethical approval of all relevant bodies and that such approvals are acknowledged within the manuscript. Written informed consent was obtained from the patient for publication of this case report and any accompanying images.

\section{Acknowledgments}

We would like to thank to the paramedical team of the surgery department of the Mohamed Taher el Maamouri.

\section{References}

1. Zachariah SK, Fenn M, Jacob K, Arthungal SA, Zachariah SA. Management of acute abdomen in pregnancy: current perspectives. Int J Womens Health. 2019;11:119-134. doi:10.2147/IJWH.S151501

2. Zachariah SK, Fenn MG. Acute intestinal obstruction complicating pregnancy: diagnosis and surgical management. BMJ Case Rep. 2014;2014:bcr2013203235. doi:10.1136/bcr-2013-203235

3. Skubic JJ, Salim A. Emergency general surgery in pregnancy. Trauma Surg Acute Care Open. 2017;2(1):e000125. doi:10.1136/tsaco-2017-000125

4. Robertson R, Wu L. Adhesive small bowel obstruction in pregnancy and the use of oral contrast media: a case report. J Surg Case Rep. 2020;2020(3):rjaa018. Published 2020 Mar 6. doi:10.1093/jscr/rjaa018

5. Moriyama Y, Imai K, Nakano T, Kotani T, Kikkawa F. Somatic symptom disorder manifested as acute abdominal pain during pregnancy preceding perinatal depression: a case report. Arch Womens Ment Health. 2019;22(2):301-4. doi:10.1007/s00737-018-0863-9

6. Daimon A, Terai Y, Nagayasu Y, et al. A Case of Intestinal Obstruction in Pregnancy Diagnosed by MRI 
and Treated by Intravenous Hyperalimentation. Case Rep Obstet Gynecol. 2016;2016:8704035. doi: $10.1155 / 2016 / 8704035$

7. Nezhat CH, Kavic MS, Lanzafame RJ, Lindsay MK, Polk TM, editors. Non-Obstetric Surgery During Pregnancy [Internet]. Cham: Springer International Publishing; 2019 [cited 2020 Jun 13]. Available from: http://link.springer.com/10.1007/978-3-319-90752-9

8. ten Broek RP, Issa Y, van Santbrink EJ, et al. Burden of adhesions in abdominal and pelvic surgery: systematic review and met-analysis. BMJ. 2013;347:f5588. doi:10.1136/bmj.f5588
9. Leyendecker JR, Gorengaut V, Brown JJ. MR imaging of maternal diseases of the abdomen and pelvis during pregnancy and the immediate postpartum period. Radiographics. 2004;24(5):1301-1316. doi:10.1148/rg.245045036

10. Ten Broek RPG, Krielen P, Di Saverio S, et al. Bologna guidelines for diagnosis and management of adhesive small bowel obstruction (ASBO): 2017 update of the evidence-based guidelines from the world society of emergency surgery ASBO working group. World $J$ Emerg Surg. 2018;13:24. Published 2018 Jun 19. doi:10.1186/s13017-018-0185-2 